\title{
LXXIII. The velocities of the ions of alkali salt vapours at high temperatures
}

\author{
Harold A. Wilson M.A. D.Sc. M.Sc. F.R.S.
}

To cite this article: Harold A. Wilson M.A. D.Sc. M.Sc. F.R.S. (1906) LXXIII. The velocities of the ions of alkali salt vapours at high temperatures, Philosophical Magazine Series 6, 11:66, 790-793, DOI: 10.1080/14786440609463499

To link to this article: http://dx.doi.org/10.1080/14786440609463499

曲 Published online: 16 Apr 2009.

Submit your article to this journal $\lceil\pi$

Џ Article views: 2

Q View related articles $\square$ 
LXXIII. The Velocities of the Ions of Alkali Salt Vapours at High Temperatures. By Harold A. Wilson, M.A., D.Sc., M.Sc., F.R.S., Fellow of Trinity College, Cambridge, and Professor of Physics, King's College, London*.

$\mathbf{I}^{\mathrm{N}}$ $\mathrm{N}$ a paper on "The Electrical Conductivity of Flames containing Salt Vapours," Phil. Trans. A. vol. 192, 1899, the writer gave an account of a series of experiments which included measurements of the velocities of the ions of salt vapours in flames and in hot air. The method employed was to find the electric intensity necessary to make the ions move against a stream of gas moving with a known velocity. The following table gives the results obtained:-

(1) Positive ions of various salts of Cæsium, Rubidium, Potassium, Sodium, and Lithium in a Bunsen flame. Velocity $62 \mathrm{cms}$. per sec. for one volt per $\mathrm{cm}$.

(2) Negative ions of same salts in a Bunsen flame. Velocity $1000 \mathrm{cms}$. per sec.

(3) Positive ions of salts of Crsium, Rubidium, Potassium, Sodium, and Lithium in air at $1000^{\circ} \mathrm{C} .7 .2 \mathrm{cms}$. per sec.

(4) Positive ions of salts of Barium, Strontium, and Calcium in air at $1000^{\circ} \mathrm{C}$. $3.8 \mathrm{cms}$. per sec.

(5) Negative ions of salts of Barium, Strontium, Calcium, Cæsium, Rubidium, Potassium, Sodium, and Lithium in air at $1000^{\circ} \mathrm{C}$. 26 cms. per sec.

In 1900 Dr. E. Marx published an account ("Ueber den Potentialfall und die Dissociation in Flammengasen," Annalen der Physik, 1900, no. 8) of a valuable series of experiments on the conductivity of flames, including determinations of the ionic velocities for different salt vapours in the flame. His method depended on observations of the potential gradient in the flame, and was quite different from that employed by the writer. He obtained for the velocity of the negative ions of any alkali salt in the flame $1000 \mathrm{cms}$. per sec. For the positive ions of any alkali salt in the flame he found the velocity to be about $200 \mathrm{cms}$. per sec.

The experiments of Dr. Marx and the writer thus agree in showing that all alkali salt vapours in flames give ions having under the same conditions nearly equal velocities, and that the velocity of the negative ions is much greater than that of the positive ions.

In 1901 the writer published a paper on the "Electrical Conductivity of Air and of Salt Vapours" (Phil. Trans. A. vol. 197,1901 ), in which it was shown that, above $1350^{\circ} \mathrm{C}$., and with an E.M.F. of over 1000 volts, all alkali salt vapours

* Communicated by the Physical Society : read March 9, 1906. 
conduct equally well if the amount of each one taken is proportional to its molecular weight. The temperature above which this result holds good was nearly the same for every salt. Above this temperature the current was independent of the temperature and of the P.D. used, provided the latter was sufficiently great. Since the lowest temperature at which this maximum current could be obtained was the same for all alkali salts, it follows that at such high temperatures the salts tried all gave ions having the same velocity; for if some salts had given ions having a smaller velocity than others, then a higher temperature and larger P.D. would have been required to obtain the maximum current with these salts.

The writer has recently, in collaboration with Mr. E. Gold, B.A., carried out a series of experiments on the conductivity of flames containing salt vapours for rapidly alternating currents. We bave found that the conductivity for rapidly alternating currents varies as the square root of the corresponding conductivity for steady currents. It is shown in the paper*, that this result can be explained by supposing that all the salts tried give ions having equal velocities in the flame.

In 1903 Prof. Moreau published an account (Annales de Chimie et de Physique, Sept. 1903) of some measurements of the velocites of the ions of salt vapours in flames by a method which was described by the writer in the paper referred to above in 1899. Prof. Moreau found, in good agreement with the earlier work, that all the alkali salts tried gave positive ions having a velocity of about $80 \mathrm{cms}$. per sec. For the negative ions of salts of potassium and sodium, however, Prof. Moreau obtained results which do not agree with those obtained by Dr. Marx and the writer. Prof. Moreau's results for sodium and potassium salts are as follows :-

With equal molecular concentrations the velocity of the negative ions is independent of the nature of the acid radical of the salt. It varies with the metal in the inverse ratio of the square root of the atomic weight. For a particular salt vapour the velocity of the negative ion increases as the concentration of the vapour diminishes. Prof. Moreau gives the following numbers :-

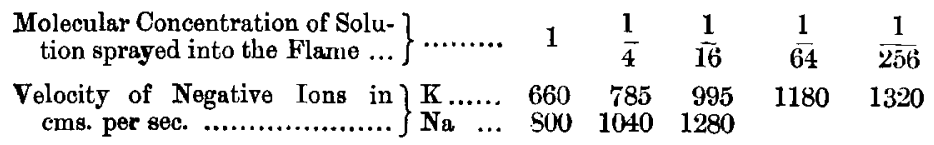

Thus with large concentrations the sodium ions seem to have larger velocities than the potassium ions.

* Phil. Mag. A pril 1906. 
The method used by Prof. Moreau was to find the P.D., between two vertical electrodes, required to make the salt ions move across from the bottom of one electrode to the top of the other. Then, assuming the electric field uniform and knowing the upward velocity of the gases between the electrodes, the velocity of the ions was calculated. Now the electric field in a flame is very far from being uniform, but it is no doubt nearly the same in different cases when the conductivity of the flame is the same. Consequently, if we compare Prof. Moreau's results for potassium salts with his results for sodium salts, taking such concentrations that the flame has the same conductivity for the potassium salts as for the sodium salts, then we ought to get the relative velocities of the potassium and sodium salt ions free from error due to variations of the potential gradient with the conductivity of the flame.

Potassium salts conduct about four times as well as sodium salts when the concentration is small, so that Prof. Moreau's numbers may be tabulated thus :-

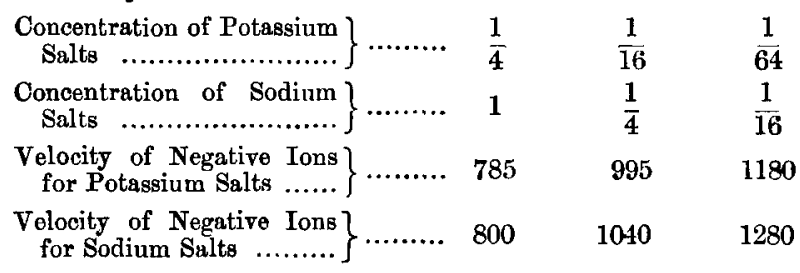

Thus, comparing velocities with concentrations giving nearly equal conductivities, the velocities found by Prof. Moreau are very nearly the same for potassium salts as for sodium salts. The apparent variation of the velocity with the concentration of the salt vapour is no doubt due to the variation of the fall of potential between the electrodes with the conductivity, and not to any real variation of the velocity with the concentration.

The mean of Prof. Moreau's results for the velocity of the negative ions is about $1000 \mathrm{cms}$. per sec., and so agrees very well with the earlier results obtained by Dr. Marx and the writer.

If Prof. Moreau were correct in supposing that the velocity of the negative ions varies inversely as the square root of the atomic weight of the metal, it would follow that salt vapours are ionized into a metal ion carrying a negative charge and a positive ion the same for all salts. Such a conclusion is altogether inconsistent with our knowledge of the ionization of salts. 
If all salts give positive and negative ions having the same velocities in a flame, this can be explained by supposing that a salt molecule emits a corpuscle which is the negative ion, and that the positively charged salt molecule forms an aggregate of molecules whose size depends only on the charge, and so is the same for all salts. This view is consistent with the fact that the velocity of the positive ions is only about $60 \mathrm{cms}$. per sec. while that of the negative ions is $1000 \mathrm{cms}$. per sec. According to Prof. Moreau's results, the positive and negative ions ought to have nearly equal velocities, for the atomic weight of the metals is comparable with the molecular weight of the acid radicals.

The experiments done by the writer in 1899 showed that lithium ( $\mathrm{Li}=7$ ) salts give ions having the same velocities as the ions from cæsium ( $\mathrm{Cs}=133$ ) salts; which proves clearly that the velocity of the negative ions does not vary inversely as the square root of the atomic weight of the metal-a conclusion which Prof. Moreau has drawn from experiments on potassium $(\mathrm{K}=39)$ and sodium ( $\mathrm{Na}=23$ ) salts.

It has been shown by Prof. Lenard that the salt vapour emitting light in flames moves in a strong electric field as though it were positively charged. I have verified this result, which clearly proves that the metal goes to form the positive ions, for the light is undoubtedly emitted by the metal atoms and not by the acid radical of the salts.

I think therefore that the view that all alkali salts in flames give ions having nearly the same velocities is really supported by Prof. Moreau's observations as well as by those of Dr. Marx and the writer.

LXXIV. On some Properties of the a Rays from Radiothorium. (I.) By O. HAHN, Ph.D.*

I $\mathrm{N}$ a previous paper $t$, $\mathrm{I}$ have given an account of the methods of separation and the radioactive properties of a very active substance, called radiothorium, which was prepared from the Ceylon mineral thorianite. It was shown that radiothorium was probably a slowly changing product of thorium-the latter is then supposed to be inactive-which lies between thorium and thorium-X.

Radiothorium possesses in an intense degree all the radioactive properties of thorium, for it gives rise to thorium-X,

* Communicated by Prof. E. Rutberford, F.R.S.

† Proc. Roy. Soc. March 1905; Jahrbuch. d. Radiaktivität, II. 3. 1905. Phil. Mag. S. 6. Vol. 11. No. 66. June 1906. $3 \mathrm{~F}$ 